\title{
PROPERTIES OF AIMg3 ALUMINIUM ALLOY JOINTS WELDED BY ELECTRON BEAM MELTING
}

\author{
Mirosław Czechowski \\ Gdynia Maritime University, Faculty of Marine Engineering \\ Morska Street 81-87, 81-225 Gdynia, Poland \\ tel.: +48585586 346, fax: +48585586399 \\ e-mail:m.czechowski@wm.umg.edu.pl
}

\begin{abstract}
Electron beam welding, called electron welding consists in penetrating the elements being welded with heat obtained from the elements' bombardment in vacuum with concentrated electron beam of high energy. Concentration of the electron beam of high kinetic energy in a very small space results in generating the heat of high concentration causing melting of material in high depth. During the metal melting the electron beam makes a narrow weld of little heat affected zone (HAZ). This paper presents the test results on selection of parameters of electron beam welding of $12 \mathrm{~mm}$ thickness sheets of AlMg3 aluminum alloy. The beam electron melting through was carried out in vacuum by means of the welding machine WS-15 KW/100 KV. Before melting, the sheets were degreased in tetrachloroethylene and oxides were removed with $15 \%$ solution $\mathrm{Na}_{2} \mathrm{Co}_{3}$. The influence of electron beam melting through of sheets on their mechanical properties was tested as well as resistance to stress corrosion cracking and resistance to corrosion in fast seawater flow $(10 \mathrm{~m} / \mathrm{s})$. The slow strain rate stress corrosion tests in the air and artificial seawater were performed. It was found that electron beam melting through of the AlMg3 alloy does not decrease the mechanical properties in comparison to the native material. The crack during the static tension test had ductile character and proceeded in the native material. AlMg3 alloy melting with electron beam shows a very good stress corrosion resistance.
\end{abstract}

Keywords: electron beam welding, aluminium alloy, stress corrosion

\section{Introduction}

Electron beam welding, called electron welding consists in penetrating the elements being welded with heat obtained from the elements' bombardment in vacuum with concentrated electron beam of high energy up to $1.5 \times 105 \mathrm{~W} / \mathrm{mm}^{2}$ [1]. Concentration of the electron beam of high kinetic energy in a very small space results in generating the heat of high concentration causing melting of material in high depth. During the metal melting the electron beam makes a narrow weld of little heat affected zone (HAZ). A very large density of electron beam power and the possibility to adjust it accurately and flexibly allow for making welds in one passage up to $250 \mathrm{~mm}$ thick in case of steel and up to $450 \mathrm{~mm}$ thick in case of aluminum; the relation between the weld's height to its width ranges from 1:1 to 50:1 [1]. High heat conduction of aluminum alloys does not affect the welding process since high concentration of electron beam power heats the welded element quasi-adiabatically. Oxidation is liquidated and hydrogen porosity limited in the welding process due to application of vacuum. Electron welding is in principle the welding process with no additional material. All the aluminum alloys welded in arc welding may undergo electron welding [1]. The welds made by the electron beam joint are cleaner than the native material because during the melting process the gases coming from the welding pool are continuously released.

\section{Selection of welding parameters}

The sheets of $5754 \mathrm{H} 111$ [AlMg3] alloy of $12 \mathrm{~mm}$ thickness were used in the tests. Before the joints were made for further tests, preliminary tests were carried out to determine optimal parameters of welding. As electron, welding most often consists in melting through the alloy 
without any additional material it has been assumed that the root of the weld should be placed in solid material, which to some extent corresponds to the so-called insert welding [3]. In that case, the possible defects of the bottom and the root of the weld do not affect the joint's qualities. Therefore, the defects were not subject of research. The welding conditions were selected taking into account the quality of the weld assessed on the grounds of the course of the melting through process, shape of the weld's face, depth of melting and structure of the weld.

The beam electron melting through was carried out in vacuum by means of the welding machine WS-15 KW/100 KV (Przemyslowy Instytut Elektroniki) [3]. Before melting, the sheets were degreased in tetrachloroethylene and oxides were removed with $15 \%$ solution Na2Co3. The applied parameters during the tests are presented in Tab. 1, while the selected structures after macroscopic tests are presented in Fig. 1-4. The samples, for macroscopic tests, were etched with the following reagents: Ma6Al and Ma1 Al pursuant to $\mathrm{PN}-75 / \mathrm{H}-04512$.

Tab. 1. Parameters of electron beam welding of AlMg3 alloy

\begin{tabular}{|c|c|c|c|c|c|c|c|c|}
\hline \multirow{2}{*}{$\begin{array}{l}\text { Sample } \\
\text { marking }\end{array}$} & \multirow{2}{*}{$\begin{array}{c}\mathrm{U}_{\mathrm{a}} \\
{[\mathrm{KV}]}\end{array}$} & \multirow{2}{*}{$\begin{array}{c}\mathrm{J}_{\mathrm{a}} \\
{[\mathrm{mA}]}\end{array}$} & \multirow{2}{*}{$\begin{array}{c}\mathrm{J}_{0} \\
{[\mathrm{~mA}]}\end{array}$} & \multirow{2}{*}{$\begin{array}{c}\mathrm{V}_{\mathrm{s}} \\
{[\mathrm{cm} / \mathrm{min}]}\end{array}$} & \multicolumn{2}{|c|}{ Beam oscillation } & \multirow{2}{*}{$\begin{array}{c}\mathrm{K} \\
{[\mathrm{KW}]}\end{array}$} & \multirow[t]{2}{*}{ Fig. No } \\
\hline & & & & & $\overline{\mathrm{F} \text { [Hz] }}$ & $\mathrm{A}[\mathrm{mm}]$ & & \\
\hline E3 & 72.5 & 60 & 12.3 & 100 & 812 & 0.2 & 4.35 & Fig. 1 \\
\hline E4 & 72.5 & 60 & 12.3 & 100 & 812 & 0.5 & 4.35 & Fig. 2 \\
\hline E3(404) & 72.5 & 52 & 10.85 & 100 & 812 & 0.5 & 3.77 & Fig. 3 \\
\hline
\end{tabular}

Ua-anode voltage , J a-beam current, Jo-focusing current, Vs-welding speed , F-frequency, A-amplitude, $K$ - beam's power

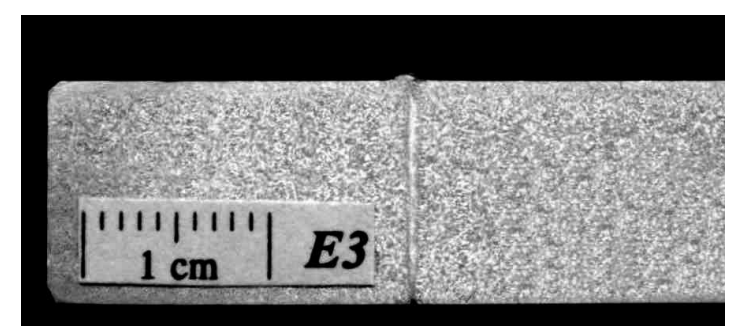

Fig. 1. AlMg3 alloy melting with electron beam through the sheet; the face of the weld is concave, up to $2.2 \mathrm{~mm}$ wide; narrow weld of equal width; the root effluent all over the melting length

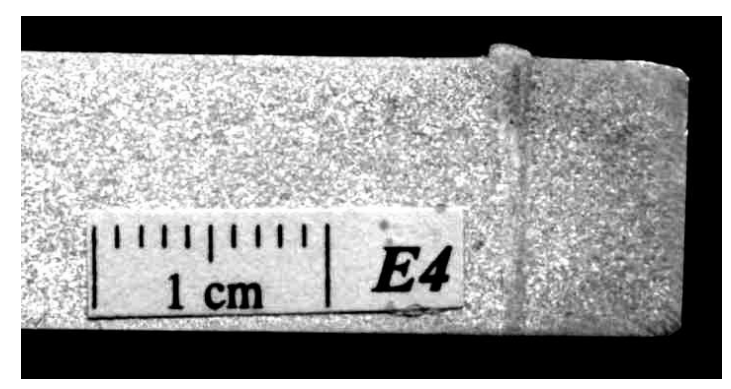

Fig. 2. Melting all over the thick sheet. The weld's face is convex, $2.9 \mathrm{~mm}$ wide; the concave face with numerous effluents

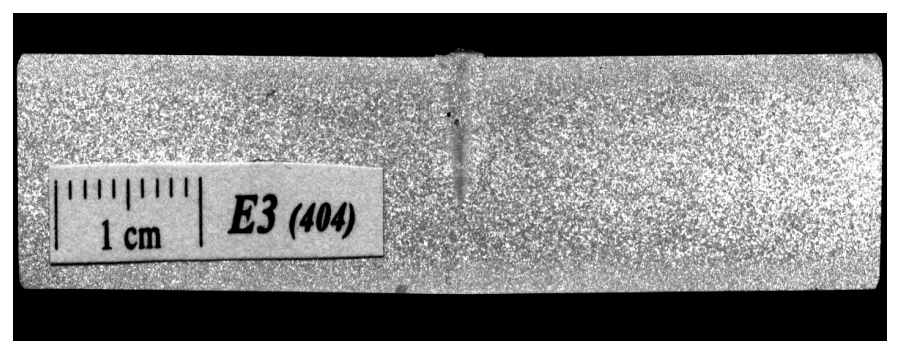

Fig. 3. The melting depth approximately $8 \mathrm{~mm}$. The face is $3.5 \mathrm{~mm}$ wide.; there are two little ball-like air sacs $\phi 0.2 \mathrm{~mm}$ (2011) pursuant to PN-EN 30042:1994 

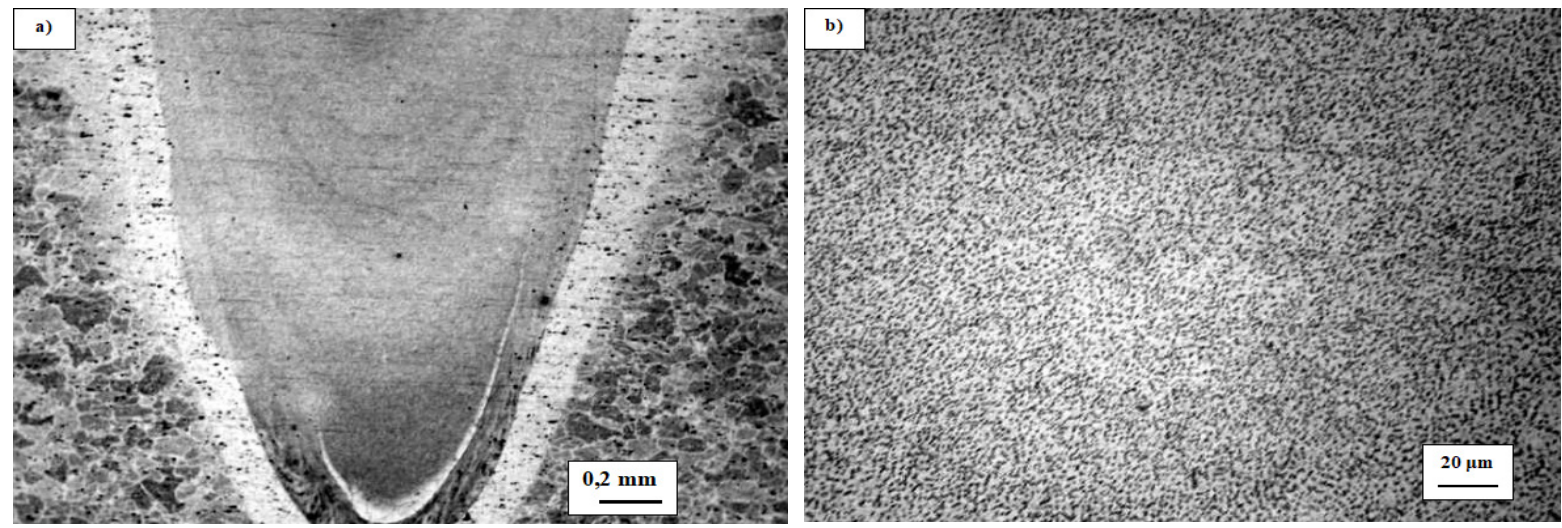

Fig. 4. Macro (a) and microstructure of the weld (b) of alloy 5754 electron beam melted

The sheets made of AlMg3 alloy were melting through for further tests, according to the assumptions, so that the weld's root was placed in the solid material, applying the same parameters, which were used for E5 sample - according to Tab. 1.

The tests to welding the AlMg4.5Mn alloy, of larger content of magnesium, with electron beam failed. The welds were porous with many air sacs. It was also difficult to obtain vacuum in the welding machine. The alloy components of high vapour pressure $-\mathrm{Mg}, \mathrm{Zn}, \mathrm{Mn}-$ might have been the reasons for such difficulties. Low pressure results in degassing of chemical elements of high vapour pressure causing porosity of the weld and unstable operation of the welding machine.

\section{Tests of mechanical properties}

Tests of mechanical properties of the native material were carried out on flat samples, $\mathrm{g}=12 \mathrm{~mm}$ thick, according to PN-91/H-04310. The results are presented in Tab. 2.

Tests of mechanical properties of the welded joints were performed pursuant to the standard PN-EN 895:1995 and PN-EN 10002-1+ACI: 1998. The ambient temperature during the test was $21.5^{\circ} \mathrm{C}$. The sample's dimensions were sat up according to PN. The mechanical properties of the tested materials are presented in Tab. 2.

Tab. 2. Mechanical properties of the native material and the alloy melting through with electron beam (average values from four samples)

\begin{tabular}{|l|c|c|c|}
\hline \multirow{2}{*}{ Material } & Tensile strength & Yield strength & Elongation \\
\cline { 2 - 4 } & {$[\mathrm{MPa}]$} & {$[\mathrm{MPa}]$} & {$[\%]$} \\
\hline $\mathrm{AlMg}$ / native material & 201 & 110 & 26.8 \\
\hline $\mathrm{AlMg} 3$ / melting with electron beam & 200.2 & 116.5 & 26.7 \\
\hline
\end{tabular}

Melting through with electron beam of AlMg3 alloy in vacuum did not affect the mechanical properties in any way in comparison to the native material. The crack during the static tension test had ductile character and proceeded in the native material (Fig. 5).

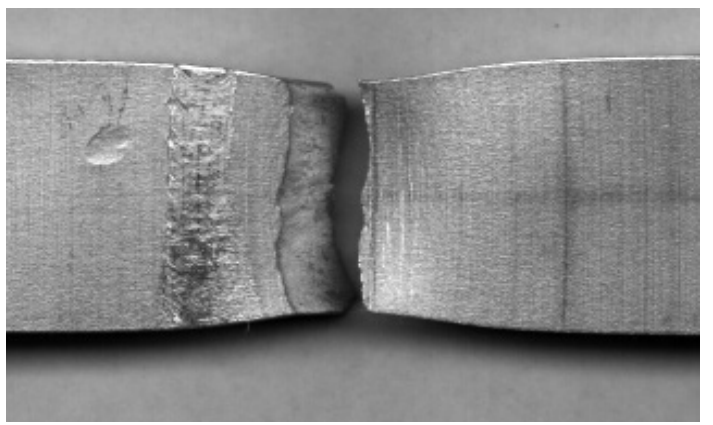

Fig. 5. The sample after the static tension test with a visible place of electron beam melting 


\section{Tests of corrosion resistance}

The stress corrosion tests were carried out with the slow strain rate test (10-6s -1$)$, pursuant to PN-EN ISO 7539-7. The parameters measured during the tests included: time to failure $-\mathrm{T}[\mathrm{h}]$, obtained maximum load - F [N], fracture energy (the surface of the diagram under strainelongation curve) $-\mathrm{E}[\mathrm{MJ} / \mathrm{m} 3]$, the sample's relative elongation $-\mathrm{A} 10[\%]$, max. tensile stress $-\mathrm{R}$ $[\mathrm{MPa}]$ and reduction-in-area $-\mathrm{Z}[\%]$. The tests were performed on smooth cylindrical samples in air (air) and artificial seawater $(\mathrm{NaCl})$. The fracture area was analysed by means of electron scanning microscope. The objective of the tests was to determine the influence of electron melting through of AlMg3 alloy sheet to corrosion stress resistance in artificial seawater.

The test results of resistance to stress corrosion cracking in the native material and the samples melting with electron beam (Ele) are presented in Tab. 3, which provides the average values of four measurements.

Tab. 3. Results of slow strain rate tests of AlMg3 alloy and AlMg3 alloy melting through with electron beam (Ele) in the air (air) and seawater $(\mathrm{NaCl})$

\begin{tabular}{|c|c|c|c|c|c|}
\hline Alloy & T.S. & $\begin{array}{c}\text { Fracture } \\
\text { energy } \\
{\left[\mathrm{MJ} / \mathrm{m}^{3}\right]}\end{array}$ & $\begin{array}{c}\text { Elongation } \\
\mathrm{A} \\
{[\%]}\end{array}$ & $\begin{array}{c}\text { Reduction-in- } \\
\text { area } \\
\mathrm{Z}[\%]\end{array}$ & $\begin{array}{c}\text { Time to failure } \\
{[\mathrm{h}]}\end{array}$ \\
\hline $\mathrm{AlMg}]$ & 203.8 & 44.85 & 24.40 & 62.3 & 40.7 \\
\hline $\mathrm{AlMg} 3-\mathrm{NaCl}$ & 203.3 & 42.80 & 24.72 & 63.3 & 40.9 \\
\hline $\mathrm{AlMg} 3 / \mathrm{Ele}-\mathrm{air}$ & 201.0 & 41.17 & 23.72 & 62.0 & 39.4 \\
\hline $\mathrm{AlMg} / \mathrm{Ele}-\mathrm{NaCl}$ & 202.5 & 43.54 & 24.60 & 60.4 & 40.9 \\
\hline
\end{tabular}

The results proved a very good resistance to stress corrosion of AlMg3 alloy. The values of the measured particular parameters obtained during exposure in the air as well as artificial seawater vary. In case of the samples strained in air the fracture, area showed deformation of the solid solution, proceeding destruction of the sample. Visible numerous dimples and different stages of micro voids' coalescence are the evidence (Fig. 6). For the samples strained in the artificial seawater morphology of the observed fractures was very close to that appearing in the samples strained in the air.

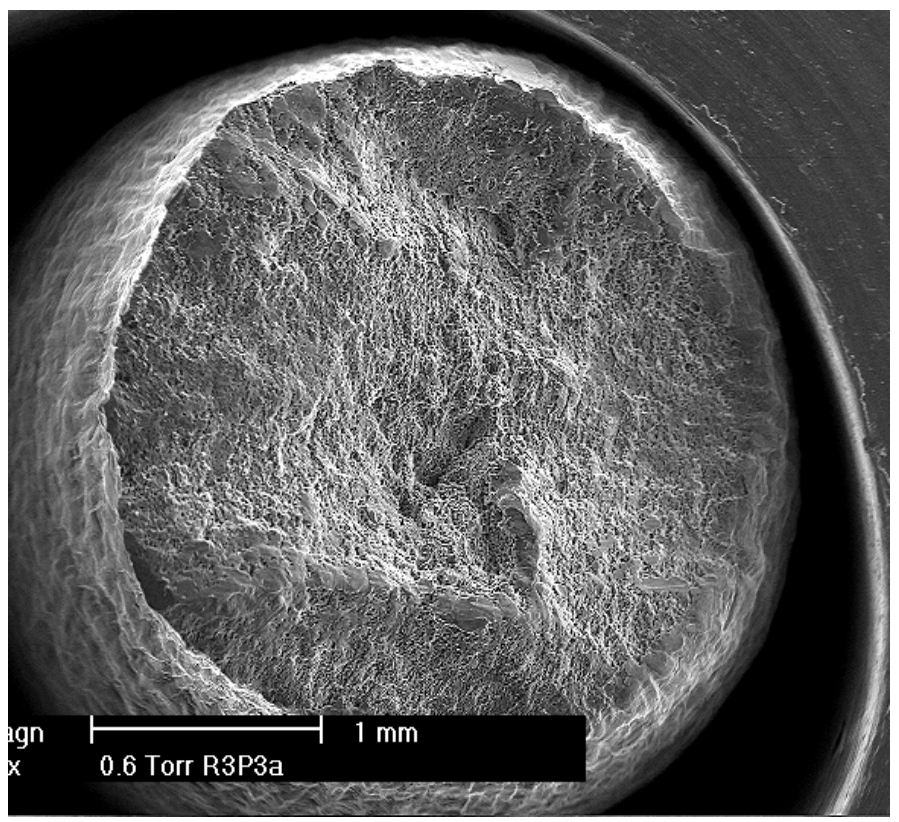

Fig. 6. The sample strained in the air; ductile cracking in the native material 
The AlMg3 alloy samples melting with electron beam plastic cracked in the native material beyond the place of melting. The samples' fractures were similar to the fractures obtained in AlMg3 alloy.

Two tested samples melting with electron beam cracked in the line of melting through. The reason for this quasi-fissile cracking were the defects (incomplete fusion) caused by the process of melting. The fractures with the defects are seen in Fig. 7.

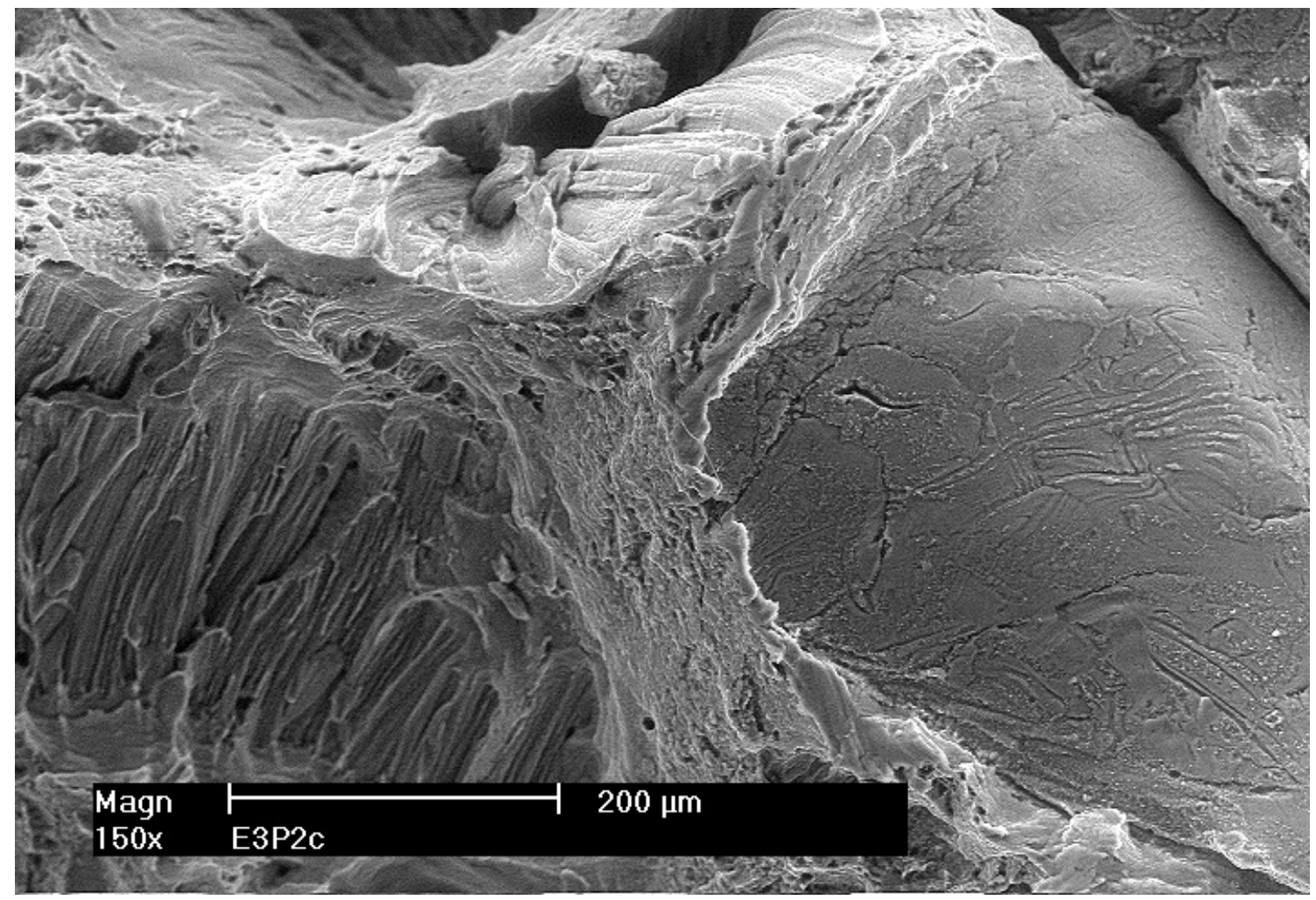

Fig. 7. The sample broken in the place of electron beam melting with a little defect (incomplete fusion)

The tests for resistance in fast flow seawater consisted in exposure of the joints melting with electron beam in the so-called centrifuge, which ensures flow of water along the sample surface at a speed of $10 \mathrm{~m} / \mathrm{s}$. The objective of test was to determine the degree of corrosion (accelerated dynamic method) and its location in the joint's area. After completion of the tests the samples were dismantled, the products of corrosion removed and the depth of corrosion decrements measured with accuracy of $0.01 \mathrm{~mm}$. For the samples made of $\mathrm{AlMg} 3$, alloys melting through with electron beam no corrosion decrements were found. This means that the resistance to corrosion in fast flow of seawater is very good.

\section{Summary}

The tests allowed for drawing the following conclusions:

1. It is possible to weld AlMg3 alloy with electron beam by melting through of the material using no additional materials. The alloy melting does not affect negatively in tensile tests properties. The samples (apart from those with macro defects) cracked in the native material beyond the place of melting;

2. The AlMg3 alloy sheets melting through with electron beam show a similar resistance to stress corrosion in the seawater as the native material and very good resistance to corrosion in fast flow seawater. 


\section{References}

[1] Klimpel, A., Technologia spawania i cięcia metali, Wyd. Politechniki Śląskiej, Gliwice 1997.

[2] Grodzinski, A., Czopik, A., The application of electron beam joining for vacuum parts, Elektronika, XXXIX, 5, p. 5, 1998.

[3] Wójcicki, S., The correlation between operating parameters of electron beam welding machine WS - $15 \mathrm{KW/100} \mathrm{kv} \mathrm{and} \mathrm{quality} \mathrm{of} \mathrm{welds,} \mathrm{Elektronika,} \mathrm{XXXVIII,} \mathrm{3,} \mathrm{p.} \mathrm{30,} 1997$.

Manuscript received 14 March 2019; approved for printing 28 June 2019 